\section{Nickelallergie: trotz Regulierung nach wie vor häufig}

Ahlström MG et al. Nickel allergy in a Danish population 25 years after the first nickel regulation. Contact Dermatitis 2017; 76: 325 - 332

1990 wurde in Dänemark eine NickelRegulierung eingeführt, seit 2001 die EU Nickel Directive vollständig in EU-Ländern umgesetzt. Die Zahl der Nickel-Allergien ist trotzdem nach wie vor hoch: Selbst bei jungen Menschen, die erst nach Einführung der Regulierung sensibilisiert wurden, liegt die Prävalenz über $10 \%$. Eine dänische Studie hat sich diese Nickel-Allergien 25 Jahre nach Einführung der ersten Regulierung genauer angesehen.

Alle Patienten der Dermatologie- und Allergologie-Abteilung des Krankenhauses im dänischen Gentofte, die in den vergangenen 5 Jahren ein positives PatchTest-Resultat auf Nickelsulfat hatten, bekamen einen Fragebogen zugeschickt. Sie sollten Angaben dazu machen, welche Kontakte zu der Dermatitis geführt hatten und welche Kontaktzeiten üblicherweise der Hautreaktion vorausgehen. 342 Patienten füllten den Fragebogen aus (knapp zwei Drittel der Angeschriebenen).

\section{Erste Symptome nach}

\section{Minuten}

Ohrringe waren mit großem Abstand der häufigste Auslöser von Nickelallergien nach Umsetzung der EU-Direktive, gefolgt von anderen Schmuckgegenständen, Knöpfen an Kleidung, Gürtelschnallen und Armbanduhren. Bei 21,4\% der Befragten dauerte es maximal 10 Minuten, bis erste Symptome einer Hautreaktion auftraten, bei 30,7\% maximal $30 \mathrm{Mi}$ nuten. Bei 6,6\% dauerte es aber auch nur 2 Minuten.

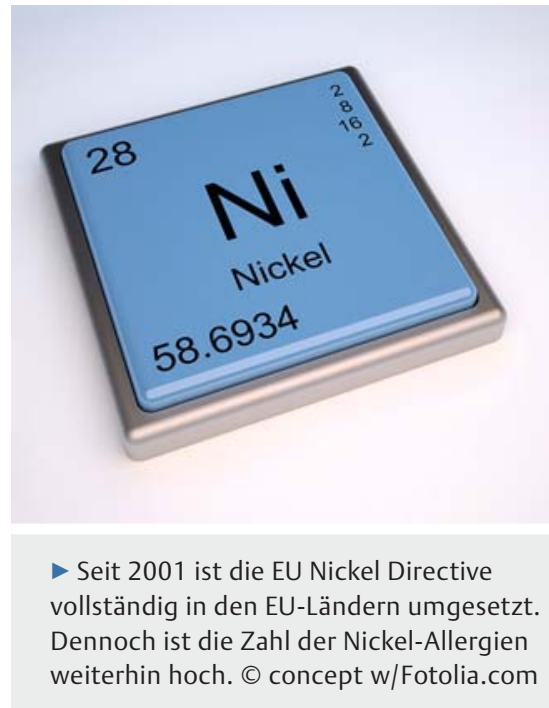

eher selten als Allergieauslöser angegeben, relativ häufig aber Metallhaken an Unterwäsche.

Die nach wie vor hohe Zahl der NickelAllergien wirft die Frage auf, ob die Regulierungen ausreichend vor Kontakt schützen. Die EU Nickel Directive hat sich als ziemlich effektiv erwiesen für Frauen, die niemals ihre Ohren haben durchstechen lassen. Für Verwenderinnen und Verwender von Ohrringen scheint die Schutzwirkung jedoch verbesserungswürdig.

Und - Regulierung oder nicht: Schmuck mit hohem Nickelgehalt wurde in diversen EU-Ländern gefunden, mit Nickelwerten zum Teil deutlich über den EUGrenzwerten.

Wie in anderen Studien waren Frauen sehr viel häufiger von Kontaktdermatitis betroffen - die Ratio betrug hier 13:1. Grund ist wahrscheinlich ihre höhere Exposition - besonders durch Ohrringe, die sich ja auch in dieser Erhebung als Hauptverursacher hervortun. Der Beginn der Kontaktdermatitis lag für Frauen durchschnittlich bei 16 Jahren, für Männer bei 18 .

\section{Durchstechen: in der Regu- lierung nicht vorgesehen}

Auch und gerade jene Patienten, die sich erst nach der Nickel-Regulierung sensibilisiert hatten - also jene unter 25 Jahren und alle, bei denen die Symptome erstmalig innerhalb der vergangenen 10 Jahre aufgetreten waren - beschreiben Ohrringe als Auslöser der Allergie. Da beim Stechen der Ohrringe die Hautbarriere durchbrochen wird, hat das Metall hier eine besondere Angriffsfläche. Die zentralen Grenzwerte der Nickel-Regulierung beziehen sich hingegen nur auf den Kontakt des Metalls mit intakter Haut.

Auch bei intakter, nicht durchstochener Haut spielt die Dauer des Hautkontakts eine Rolle. So wurden etwa Mobiltelefone, Computer, Werkzeug und Scheren
FAZIT

Trotz Regulierung scheint die Nickelexposition nicht nennenswert abgenommen zu haben. Ohrringe spielen eine besonders große Rolle - sowohl bei der Sensibilisierung als auch bei der Aufrechterhaltung der Kontaktallergie. Andere häufig allergisierende Gegenstände sind Knöpfe, Gürtelschnallen und Armbanduhren.

Dr. Nina Drexelius, Hamburg 